\title{
A ASSIMETRIA SOCIAL NA OBRA DE KATHERINE MANSFIELD
}

\section{Bruna Viedo Kich ${ }^{1}$}

Resumo: Katherine Mansfield é um dos nomes mais proeminentes da curta ficção em língua inglesa. Nascida em Wellington, Nova Zelândia a autora viveu um longo período na Europa, onde começou a produzir a sua obra. Levando em conta o olhar crítico e a sensibilidade da autora nas questões de ordem social, este trabalho investiga a representação da assimetria social nos contos: Festa ao ar livre e Casa de bonecas através da técnica impressionista proposta por Ferguson e dos símbolos bachelardianos reunidos por Alvarez Ferreira.

Palavras-chave: Assimetria social. Impressionismo. Mansfield. Simbologia.

Abstratc: Katherine Mansfield is one of the most prominent names in English short fiction. She was born in Wellington, New Zealand and live a long period in Europe, where she started to produce her work. Considering the author's critical view and sensibility in social order questions, this article investigates the social asymmetry in the short story: The Garden Party and The Doll's House through the impressionist technique proposed by Ferguson and the bachelardian symbols gathered by Alvarez Ferreira.

Keywords: Social asymmetry. Impressionism. Mansfield. Simbology.

\section{INTRODUÇÃO}

A produção literária de Katherine Mansfield traçou fortes nuances de sensibilidade no que diz respeito às relações humanas, emoldurando o legado do período modernista: a análise psicológica. Conhecida pelos críticos literários por ser uma autora dedicada à representação das experiências inerentes a cada indivíduo, Mansfield reflete em seus contos um enredo ambíguo, que permite um olhar mais atento acerca da humanidade. Carpeux descreve a autora como uma artista de sensibilidade extrema: "Os "grandes" acontecimentos, os que todo mundo observa, ela os desprezava; dedicou-se à representação meticulosa de acontecimentos e sentimentos minúsculos, que não modificam a vida, mas que indicam as modificações imperceptíveis de vidas" (Carpeaux, 1968, p. 139).

Segundo Head (2009), o desejo de materializar na obra pequenos sentimentos desprezados é a nova preocupação modernista - com um enredo

\footnotetext{
${ }^{1}$ Graduanda em Letras Inglês e Literaturas de Língua Inglesa na UFSM. Bolsista PIBIC. E-mail: brunavkich@gmail.com 
que conota mais do que denota. Ferguson (1994) define a característica principal desse novo período literário como uma representação das experiências individuais de cada ser e aponta que, a partir desse momento, a imitação passa a ser o "sentir" e o "parecer" ao contrário "da imitação de como as coisas são no mundo real".

Com o desenvolvimento do modernismo, a produção literária sofreu influência da análise psicológica, essa ganhando densidade, enquanto a ação do enredo deixava de ser o foco principal. Carpeaux observou que, progressivamente, as características realistas-naturalistas em obras foram decaindo de "uma fotografia da realidade com ou sem retoques, para tornar-se lembrança ou associação vaga através daquela espécie de sonho que se chama arte" (Carpeaux, 1968, p. 138).

$\mathrm{Na}$ sua obra, Katherine Mansfield apresenta sempre como centro da narrativa uma personagem feminina que, ao decorrer do enredo, em um ambiente doméstico, ao passar por uma experiência significante, sofre uma grande transformação. Assim, Mansfield reafirma a preocupação estética do modernismo para expor pequenos acontecimentos cotidianos, traços que Cortázar enfatiza ao teorizar sobre o conto:

\footnotetext{
O elemento significativo do conto parecia residir principalmente no seu tema, no fato de se escolher um acontecimento real ou fictício que possua essa misteriosa propriedade de irradiar alguma coisa para além dele mesmo, de modo que um vulgar episódio doméstico, como ocorre em tantas narrativas de Katherine Mansfield [...], se converta no resumo implacável de uma certa condição humana, ou no símbolo candente de uma ordem social ou histórica. [...] propondo alguma coisa do cotidiano que vai muito além do argumento. (1994, p. 53)
}

O editor e, alguns anos depois, marido da autora, John Middleton Murry, descreveu o trabalho de Mansfield, como mais espontâneo, mais vivido, mais delicado e mais bonito, quando comparado aos de seus contemporâneos, devido a um modo peculiar de olhar a vida, como se os óculos que usasse fossem de puro cristal (1935, p. 14-15). A existência dessa aguçada sensibilidade para perceber as dissonâncias sociais presentes na sociedade da época faz com que a obra de Mansfield torne-se emblemática. Na intenção de investigar tal olhar sobre aquela sociedade, foram selecionados para análise os 
contos Festa no jardim e Casa de bonecas. Os textos apresentam protagonistas femininas em situações domésticas e com enfoque na disparidade social, questão que será discutida no presente trabalho através dos símbolos bachelardianos reunidos por Alvarez Ferreira (2013) e pelo impressionismo proposto por Ferguson (1994).

\section{ASSIMETRIA SOCIAL NA OBRA DE KATHERINE MANSFIELD}

\subsection{Casa de bonecas}

Originalmente publicado em 1921, Casa de bonecas faz parte de uma trilogia de contos que remonta à infância da autora na Nova Zelândia juntamente com Prelúdio e Na baía. Essas criações renderam elogios à Mansfield por sua grande sensibilidade ao transformar personagens em reflexos da sociedade da época, fazendo o tipógrafo da autora exclamar: "Meu Deus, essas crianças são reais! (Murray, 1935, p. 10, tradução nossa).

No conto, as meninas da família Burnell - Izabel, Lotie e Kezia receberam da senhora Hay, uma amiga da família, uma casa de bonecas. $O$ brinquedo, que nomeia o conto, está associado a uma série de eventos que envolvem a vida das meninas e participa do amadurecimento da personagem principal, Kezia. Inconformada pela restrição familiar de mostrar o brinquedo a todas as meninas do colégio, exceto para as Kelveys, a heroína burla a regra imposta pela microssociedade familiar convidando as filhas da lavadeira para verem o brinquedo.

A descrição inicial do brinquedo, ainda no segundo parágrafo do texto, já demarca o uso das cores pela técnica impressionista:

Lá estava a casa de bonecas, verde espinafre, escuro e viscoso, com toques de um amarelo brilhante. Suas duas chaminezinhas falsas, coladas no telhado, eram pintadas de vermelho e branco, e a porta, num reluzente verniz amarelo, parecia um pedaço de caramelo. Quatro janelas, janelas de verdade, eram dividias em vidraças por uma larga faixa verde. Havia um pequeno alpendre, pintado de amarelo, com grandes gotas de tintas seca pendentes das bordas.

Mas era uma casinha perfeita, perfeita! Quem se importaria com o cheiro? Era parte da alegria, parte da novidade! (Mansfield, 2005, p. 19) 
O toque de diferentes cores contrastando no brinquedo chama a atenção do leitor mais atento, não apenas para uma descrição da realidade do espaço, mas também para os diversos significados e sensações que essas cores refletem. Alvarez Ferreira (2013) reflete que a cor é algo que ultrapassa os nossos sentidos e, em um primeiro momento, denota a realidade visual; entretanto, considerando o estigma poético, é uma representação de valor que vai além das formas. As cores que contrastam naquele primeiro episódio parecem ser a voz do narrador, todavia, temos a menina Kezia, dando as suas primeiras impressões sobre a casa. É nesse momento que a voz do narrador confunde-se com a da personagem, no estilo indireto livre:

\begin{abstract}
A narrativa parece agora se afastar do romancista e assumir as qualidades do personagem, que agora parece "possuir" as palavras. O escritor está livre para direcionar o pensamento informado, para dobrá-los às palavras do personagem. [...] Graças ao estilo indireto livre, vemos coisas através dos olhos e da linguagem do personagem, mas também através dos olhos e da linguagem do autor. Habitamos, simultaneamente, a onisciência e a parcialidade (Wood, 2011, p. 23-25)
\end{abstract}

Antonio Dimas define o espaço como algo que "contém dados de uma realidade que, numa instância posterior, pode alcançar uma dimensão simbólica" (1985, p. 20). O que é evidenciado por Kezia através dessa descrição é um reflexo de uma casa que não combina entre si, que está desintegrada entre seus pedaços e não apresenta uma homogeneidade ou harmonia. Essa ideia só pode ser entendida na relação cor-cheiro que a autora expõe. Enquanto tudo, em um primeiro momento, beirava a perfeição do visual, o cheiro não encobria tudo que estava por detrás do que fora dito perfeito. Cor e cheiro na casa, eram dois elementos complementares, mas de polaridades totalmente opostas. Quando o brinquedo torna-se quase um personagem, que reflete a microssociedade familiar na qual ela está inserida, alguns parágrafos depois, a desconstrução da "perfeição" se inicia:

\footnotetext{
As bonecas do pai e da mãe, estiradas, duras, como se tivessem desmaiado na sala de estar, e as duas criancinhas dormindo no andar de cima, eram realmente grandes demais para a casa de bonecas. Não combinavam com a casa. Mas o lampião era perfeito. Parecia sorrir para Kezia e dizer: "Eu moro aqui". O lampião era de verdade. (Mansfield, 2005, p. 192)
} 
É importante que se faça uma observação acerca das janelas e chaminés: enquanto as primeiras são descritas como "verdadeiras", as últimas são apontadas como "falsas". Janelas são elementos que permitem contemplar (ou não) outros ambientes, assim como são responsáveis pela emanação de luz de um outro espaço. A janela "simboliza apreensão de um mundo em devir que se oculta em seu interior" (Alvarez Ferreira, 2013, p. 109). Pelo realismo das janelas, Kezia demarca como sua personalidade transgressora iria contra a ideologia da família Kelvey, trazendo um olhar verdadeiro e próximo para as relações humanas entre classes sociais divergentes. Foi através dessa janela que a heroína percebeu "que o mundo é grande, mas ele pode ser maior na medida em que se afasta do tempo horizontal que corrói a vida, a alma e o seu coração, dissolvendo-o no fluxo do tempo." (Alvarez Ferreira, 2013, p. 109).

O olhar de Kezia sobre o espaço que a circunda, constrói o que Lins (1976 apud DIMAS, 1985, p. 20) chama de ambientação reflexa. A esse recurso, cabe a personagem detalhar as coisas, em um sistema de visão compartilhada com o narrador. É no olhar da menina que o leitor entende que a representação dos pais desmaiados é o retrato da sociedade adormecida para questões importantes, fugindo de um olhar crítico acerca de si própria. As impressões construídas pela personagem, considerando sua faixa etária (a relação de aspectos do brinquedo com elementos da própria vida familiar) e pela construção da autora, o brinquedo representa uma casa real de classe alta, com o núcleo adulto acomodado socialmente.

Kezia vai além e reflete inconscientemente sobre a sua própria participação na família, através das crianças "grandes demais para a casa". É através dessa reflexão ainda que imatura, que se nota que a personagem possui valores morais diferente dos impostos pelo núcleo familiar. Seus valores são descritos pela sua simpatia com o lampião "de verdade" e "perfeito". Essa representação ficcional da luz "tem uma dupla fonte: vem do mundo celestial para iluminar e fazer resplandecer todas as coisas e da "alma iluminante" do ser humano quando purificado e liberto das impurezas que obscurecem o seu ser" (Alvarez Ferreira, 2013, p. 118).

O mundo adulto é responsável pela projeção que as crianças protagonistas do conto possuem das diferenças de classe social. Todas, com 
exceção de Kezia, mimificam o mundo adulto, como pode ser visto no trecho abaixo:

"Quando crescer, Lil Kelvey vai ser uma criada."

"Oh, que horror!", exclamou Isabel Burnell, piscando para Emmie.

Emmie retribuiu a piscada de um jeito muito maldoso e concordou com Isabel como vira sua mãe fazer em muitas ocasiões assim. (Mansfield, 2005, p. 196).

O olhar de Kezia para as questões de condição social diverge da família e do comportamento das outras personagens. Apesar de inconsciente, devido à pouca idade da menina, o lampião é responsável por representar a diferença entre a heroína e as demais meninas. Essa passagem se torna evidente quando Isabel, a líder das irmãs está descrevendo o brinquedo para as outras colegas na escola. Quando ela terminou, Kezia começou. "Você se esqueceu do lampião, Isabel":

\footnotetext{
"Ah, sim", disse Isabel, "e tem também um lampião bem pequeno, feito de vidro amarelo, com uma cúpula branca, em cima da mesa da sala de jantar. Parece um lampião de verdade.

"O lampião é o melhor de tudo", exclamou Kezia. Ela achou que Isabel não estava valorizando suficientemente o pequeno lampião. Mas ninguém prestou a mínima atenção (Mansfield, 2005, p. 195).
}

Essa exaltação de Kezia, acerca do objeto que emana luz, percorre vários trechos do texto, sem qualquer simpatia de outras personagens. Entretanto, ao fim, quando a personagem burla as regras do núcleo familiar e mostra o brinquedo para Else e Lil Kelvey, a primeira exclama ao fim do texto "Mas eu vi a lampadinha" (Mansfield, 2005, p. 199). Essa simpatia é a criação de um vínculo de caráter entre as duas personagens.

\subsection{Festa ao ar livre}

Publicado no ano de 1921, Festa ao ar livre - encontrado em algumas traduções como Festa no jardim ou $A$ festa no jardim - gira em torno de uma grande festa que está sendo produzida pela família Sheridan. Laura, uma das filhas, é encarregada de preparar o evento. Porém, a morte de um trabalhador na calçada em frente à casa proporciona à jovem uma grande reflexão acerca das questões humanistas. Apresentado a mesma temática de Casa de 
bonecas, Festa ao ar livre apresenta uma jovem protagonista que através de uma situação cotidiana começa a se indagar acerca das diferenças de classe social e transgride as regras sociais impostas pelo ambiente familiar.

O conto, também começa com uma descrição do ambiente, dessa vez, demarcando uma aparência das festas no jardim tipicamente europeias:

\begin{abstract}
E afinal, o clima estava perfeito. Não poderiam ter dia mais perfeito para festa ao ar livre, mesmo que o tivessem encomendado. Morno, sem vento, o céu sem uma nuvem. Apenas o azul velado por uma névoa dourado-clara, como ás vezes acontece no início do verão. $O$ jardineiro acordara de madrugada, aparando e varrendo os gramados, até que a grama e as rosetas achatadas e escuras, que substituiriam os pés das margaridas, pareceram brilhar. Quanto às rosas, não poderiam deixar de sentir que sabiam ser as únicas flores que impressionam as pessoas nas festas ao ar livre; as únicas flores que todos certamente conhecem. Centenas, sim, literalmente centenas desabrocharam numa única noite: os arbustos verdes se curvaram, como se visitados por arcanjos. (Mansfield, 1997, p. 33)
\end{abstract}

O cenário no qual o enredo se desenrola é também uma casa de família de classe média alta, na qual os membros estreitam suas relações através de eventos cotidianos. A perfeição do clima ideal, na temperatura ideal com centenas de flores desabrochando, constrói a ideia de felicidade do ambiente, através da combinação de elementos de diversas cores propostos pela autora o céu límpido, o rubor das centenas de rosas, o frescor dos gramados e arbustos. É nessa idealização que o leitor compreende, por meio dos sentidos, todo o ambiente do núcleo familiar e também parte do caráter que compõe cada personagem. A grande compra de lírios pela senhora Sheridam, apesar do estranhamento inicial de Laura, compõe o ambiente de ostentação da festa no jardim oferecida pela família.

Segundo Alvarez Ferreira (2013) pode-se fazer a leitura do simbolismo da flor como um elemento ligado à ascensão de algum evento, às cores e às luzes. Sendo assim, não haveria elemento mais propício para estar em demasia em uma festa. Cada rosa daquele jardim ou os lírios comprados, não representam apenas a recriação impressionista de um espaço criado por para um dia de sonho. As flores e as cores da festa são elementos que só são entendidos e compreendidos, em totalidade, momentos depois da trama, em comparação a cena do velório. Antes desse ponto, eles representam meramente a criação de um ambiente propício à realização de uma festa e a 
ostentação de bens materiais, pois os lírios passaram a ser uma decoração extra e inata à natureza do jardim.

Laura é, desde o início do conto, identificada por dons artísticos e por isso, escolhida como a responsável pela organização da festa e interação com os operários. O leitor mergulha nos pensamentos de Laura e através deles podemos perceber o encadeamento dos códigos morais estabelecidos, bem antes de qualquer episódio ou interação trágica:

Laura partiu correndo, ainda segurando um pedaço de pão com manteiga. É tão delicioso ter uma desculpa para comer ao ar livre [...] Quatro homens, vestidos em mangas de camisa, estavam agrupados na alameda do jardim. Carregavam tábuas cobertas de rolos de telas, e tinham grandes sacas de ferramentas lançadas as costas. Impressionavam. Laura agora desejava não estar segurando seu pão com manteiga, mas não havia onde pousá-lo e não podia jogar fora de forma alguma [...]

- Bom dia - disse ela copiando a voz da mãe. (Mansfield, 1997, p. 3435)

Através desse fragmento se pode notar a excepcionalidade do ato de comer fora dos ambientes da casa através do pensamento de Laura. Wood (2011, p. ?) estabelece que através do estilo indireto livre podemos "ver através dos olhos de um personagem enquanto somos incentivados a ver mais do que ele consegue ver". Nesse momento, o código social já foi definido pelo narrador e é bem mais sutil do que em Casa de bonecas. Entretanto, a busca da identificação das personagens com a matriz do âmbito familiar ainda é a mesma; enquanto Isabel piscava para Emmie da mesma forma com via a mãe fazer, Laura busca recriar o tom de voz da mãe. Ambas as personagens recriam o mundo adulto em suas perspectivas, pois são estão na fase infantil e juvenil, ainda buscando por experiências de mundo que completem suas identidades.

Entretanto, assim como Kezia, os padrões de comportamento da família - que ao final representam o padrão de comportamento de toda uma sociedade - são sobrepostos pela própria natureza do seu caráter:

Como eram agradáveis os trabalhadores! E que bela manhã! [...] Oh, como os trabalhadores eram extraordinariamente simpáticos pensou. Porque não podia ter amigos trabalhadores, em vez dos rapazes tolos com quem dançava e que vinham jantar domingos à 
noite? Ela se daria muito melhor com homens assim. (Mansfield, 1997, p. 35-37)

As tentativas de Laura de se identificar com os valores morais préestabelecidos da própria família começam a falhar e chegam ao ápice quando a notícia do falecimento de um operário em frente a casa vem à tona. Da mesma forma como a irmã, que pede à heroína que não seja tão "extravagante", a ponto de querer parar a festa, a mãe ainda olha a filha com um toque de diversão ao the ver sofrer pelo outro. Dessa vez, são os pensamentos e impressões de Josie que o narrador traz, para complementar o quadro da tragédia:

[...] os pequenos bangalôs ficavam numa viela própria, bem ao final de uma subida íngreme que ficava até a casa. Uma rua ampla as separava. É verdade, estavam próximos demais. Eram o maior monstrengo possível e não tinham qualquer direito de estar naquela vizinhança. Eram pequenas moradias humildes, pintadas de cor de chocolate. Nos quintais só havia pés de repolho, galinhas doentes e latas vazias. A própria fumaça que saia pelas chaminés era marcada pela pobreza: pequenos fios esgarçados de fumaça, tão diferente das colunas prateadas que desenrolavam das chaminés dos Sheridan. [...] Enxames de crianças. (Mansfield, 1997, p. 47-48)

Se nos primeiros parágrafos do texto, a ambientação da residência da família Sheridan era posta, como clara, florida e iluminada, a viela dos operários é situada como algo visto com desgosto, escuro e sujo. Dimas aponta que a associação desses motivos corresponde a signos verbais, que juntos caracterizam a obra, abrindo espaço para interpretações simbólicas, podendo ser de forma acidental ou essencial. Nesse caso, a essencialidade da ambientação de dois diferentes espaços separados por uma ponte compõe uma motivação caracterizadora: "A motivação caracterizadora será heteróloga e de contraste se, ao lado da casa luxuosa, onde se celebra uma festa espetacular, percebe-se a existência de crianças famintas, remexendo as latas de lixo" (Dimas, 1985, p. 37, grifo do autor).

O espaço é ainda intensificado pela transição de Laura para a casa dos Scott. Se em Casa de bonecas, a linha que dividia as meninas da família Burnell do resto da sociedade era traçada de forma invisível, em Festa ao ar livre ela se materializa pela queda da ponte que na viela pinta com nuances de 
escuro tudo que ali se situa. No encontro com o defunto, mais um elemento simbólico marca o caráter da protagonista em relação à sua família - o chapéu. Enquanto em um breve momento Laura recebe o enfeite com alegria devido à sua sofisticação, ao entrar naquela casa o objeto a envergonha por ser o que a difere desse outro grupo social. "Perdoe meu chapéu" (Mansfield, 1997, p.59) é a marca que define a transformação interna - invisível e progressiva - da simpatia às causas humanas que uma situação doméstica provocou. O pedido de perdão de Laura é o pedido de toda a sociedade pela sua indiferença em relação aos menos abastados.

\section{CONSIDERAÇÕES FINAIS}

Como apresentado na introdução, a análise psicológica é um dos traços mais marcantes da escrita de Mansfield, acompanhado pelas situações domésticas impostas no enredo e o simbolismo que a autora usa para caracterizar seus temas. Nos dois contos, foi observada a limitação do ponto de vista e de sensações interiores pelas personagens principais - Kezia e Laura. Esse elemento foi reforçado pela ideia de permitir ao leitor uma imersão nos sentimentos e pensamentos de cada uma dessas personagens, primordialmente, através do discurso indireto livre. Esse elemento é interligado à questão da apresentação de experiências individuais de cada ser, as quais Ferguson (1994) aponta como um dos efeitos típicos da ficção moderna - a questão de identidade e integração.

A exclusão de elementos esperados no enredo tradicional - como a visita das colegas da escola à casa de bonecas ou o sucesso da festa ao ar livre -, permite uma interpretação elíptica devido aos elementos de metáfora encontrados em cada um dos enredos. Em Casa de bonecas, o sucesso da casa está presente em grande parte dos diálogos entre as meninas da escola, e o leitor assume o conhecimento delas acerca do objeto, embora esse fato não tenha sido narrado. O mesmo acontece em Festa ao ar livre, quando a caracterização de Laura, cansada, suada, permitem a percepção do sucesso da festa, que também foi omitida. 
Tais elementos caracterizam um último aspecto apontado por Ferguson (1994): a economia estilística, que demanda um leitor mais atento para uma criação muito mais conotativa do que denotativa. Nas duas obras de curta ficção, o espaço é um elemento importante para o entendimento - tanto desses elementos de análise, como para os pressupostos do leitor na sua interpretação - que permitem uma reflexão acerca das relações sociais entre diferentes esferas. Essa reflexão é criada desde a primeira linha de cada texto, embora tenha seu ápice no comportamento transgressor das personagens principais.

\section{REFERÊNCIAS}

ALVAREZ FERREIRA, Agripina Encarnación. Dicionário de imagens, símbolos mitos, termos e conceitos bachelardianos. Londrina: Eduel, 2013.

CARPEAUX, Otto Maria. A psicanálise. In: As revoltas modernistas na literatura. Rio de Janeiro: Ediouro, 1968. p. 137-140.

DIMAS, Antonio. Espaço e romance. São Paulo: Ática, 1985.

FERGUSON, Suzzane. Defining the short story: Impressionism and form. In: The new short story theories. Ohio: Ohio University Press, 1994. p. 218-230.

HEAD, Dominic. The short story: theories and definitions. In: The modernist short story: a study in theory and practice. 3. ed. Cambridge: Cambridge University Press, 2009. p. 1-36.

MANSFIELD, Katherine. A casa de bonecas. In: Katherine Manfield contos. Tradução Carlos Eugênio Marcondes de Moura e Alexandre Barbosa de Souza. São Paulo: Cosac Naify, 2005. p. 189-199.

MANSFIELD, Katherine. Festa ao ar livre. In: As filhas do falecido Coronel e outras histórias. Tradução de Luiza Lobo. Rio de Janeiro: Ediouro, 1997. p. 35-64.

MURRY, John Middleton. Introduction. In: Journal of Katherine Mansfield. 2. ed. Hamburg: Albatross Verlag, 1935. p. 7-17.

WOOD, James. Narrando. In: Como funciona a ficção. Tradução de Denise Botmann. São Paulo; Cosac Naify, 2011. p. 17-44. 